Using this method, chemical changes in the brain and reflex activity, ventricular fibrillation and methods of resuscitation are investigated and discussed. There are two major points at which clinical practice and beliefs differ from non-Soviet practice. The use of intra-arterial oxygenated blood is recommended for transfusion in severe hæmorrhage and shock and the efficiency of intravenous transfusion is questioned. The administration of pure oxygen is said to be deleterious in the early stages of resuscitation and a strength of not more than 40 per cent is recommended clinically. This recommendation is modified to exclude states of prolonged circulatory impairment, when 100 per cent oxygen may be used. The experimental results presented are not in accord with recent American work showing that oxygen at high pressures improve survival in acute hæmorrhage. Apart from this the recommendations made are very similar to those current elsewhere.

The translation by Dr. B. Haigh is easily readable and contains none of the archaicisms and woolliness seen in medical books translated by the U.S.S.R. State Publishing Houses. It can be recommended both for its intrinsic interest and as a reference work.

K. BLOOR

\section{AIDS TO ORGANIC CHEMICAL PRACTICE}

Laboratory Practice of Organic Chemistry

By Prof. G. Ross Robertson and Prof. Thomas L. Jacobs. Pp. ix +383 . (New York and London: The Macmillan Company, a division of the Crowell-Collier Publishing Company, 1962, fourth edition). $41 s$.

\section{Physical Aids to the Organic Chemist}

By M. St. C. Flett. (Elsevier Monographs: Chemistry Section.) Pp. xii + 388. (Amsterdam: Elsevier Publishing Company; New York: American Elsevier Publishing Company, Ine., 1962.) D.fl. 22.50.

THE first volume is an elementary text in wide use in the United States and now in its fourth edition. This latest revision has been carried out in the light of replies of past users to a questionnaire about necessary changes, points to be elaborated, etc., and the result, while proserving the best features of previous editions, has been brought more into line with present-day practice. The preparations themselves are good of their kind, though of a traditional character, details are clear and adequate, but one of the most useful features is the series of questions at the end of many of the experiments which serve to prompt some consideration by the student of what is actually taking place in the course of the reaction and why. There is also a series of references to somewhat more elaborate experiments to which the student can graduate after completing the salient stages of the basic course.

Simple qualitative organic analysis is dealt with in a single chapter, and the suggested procedures though succinct must noeds be somewhat sketchy within a compass of only 17 pages, though it must be said that this is a refreshing change from the usual elaborate schemes that stress trivialities and do not work in any case. One of the best features of the book is the first section (163 pages), which deals with matters of general technique and, most importantly, the simple physical principles that underlie their operation: this is clear, forthright and most useful. One criticism that can be made is that the equations included could more usefully portray what is actually believed to be taking place in the reaction rather than merely representing starting material and ond product.

The fact that many organic chemists tend to be somewhat deficient in a knowledge of the physical principles that govern their operations prompts a need not only for further investigation of such physical principles themselves but also of the vastly increasing battery of extremely powerful physical techniques that have become available to assist not only in isolating and identifying the products of chemical reaction but also, in a number of cases, following the actual course that the reaction takes. Mr. Flett's book provides an admirable summary of a number of the more important of these techniques-more particularly, chromatographic separation, including gas-liquid chromatography, zone refining, spectroscopy (including electronic absorption, infra-red, electron spin resonance and nuclear resonance methods), mass spectrometry and $\mathrm{X}$-ray crystallography.

In each case there is a short but trenchant account of the theory underlying the method and then a most useful and helpful account of its applications. One comes away with a proper realization of the types of problem a particular method can help to solve and-just as useful-those in which it is somewhat unlikely to be successful. We are spared the tedious details of particular instruments which have marred and reduced the usefulness of many endeavours of this nature in the past.

The true value of this work is that it really does concentrate on essentials and is prepared to let the more trivial details go. It is inevitable that there will be some differences of opinion about things that might have been included-I myself feel that some reference to thinlayer chromatography and counter-current distribution would have been valuable--but what is abundantly clear is that a great deal of most useful, apposite information is included within this relatively small compass. The book itself is clearly, even elegantly written, the standards of production are extremely high and it can be recom. mended unreservedly to all potential users.

Peter Sykes

\section{THE AEROPLANE ON THE WING}

\section{Aircraft Stability and Control}

By Dr. A. W. Babister. (International Series of Monographs in Aeronautics and Astronauties. Division 6: Flight Testing, Vol. 1). Pp. 700. (London and New York: Pergamon Press, 1961.) 105s. net.

A GENTLEMAN actively engaged in the manufacture A of flying machines once referred to stability theory as 'a clash of symbols'. Newcomers to the subject, encountering the ten-page tabulation which precedes Dr. Babister's text, will probably agree.

The first two parts of the book are devoted to the theory of longitudinal and lateral stability and control, with a distinctly British outlook. Indeed, several chapters are almost verbatim reproductions of now-classical R. and $M$. papers in the Report and Memorandum series of the Aeronautical Research Council. The author has performed a considerable service in collecting all this work in one volume, but the overall impression is not quite the same as that usually conveyed by one author expounding a coherent progression of ideas. For example, successive chapters on longitudinal static stability display an increasing degree of refinement largely resulting from the historical development of the subject. A criterion for static stability is defined at the beginning of Chapter 3 which, although not actually applied later, is formally at variance with that justified with the full rigour of R. and M. 2027 in Chapter 11. In view of the scope of the book, this is a rather minor criticism, completely overshadowed by such solid merits as the very full list of references at the end of each chapter: there are no less than 86 for Chapter 15.

In covering such a wide field, it is always difficult to strike a happy balance between fundamentals and applications. Operational methods as applied to response calculations are dismissed in slightly more than one page 